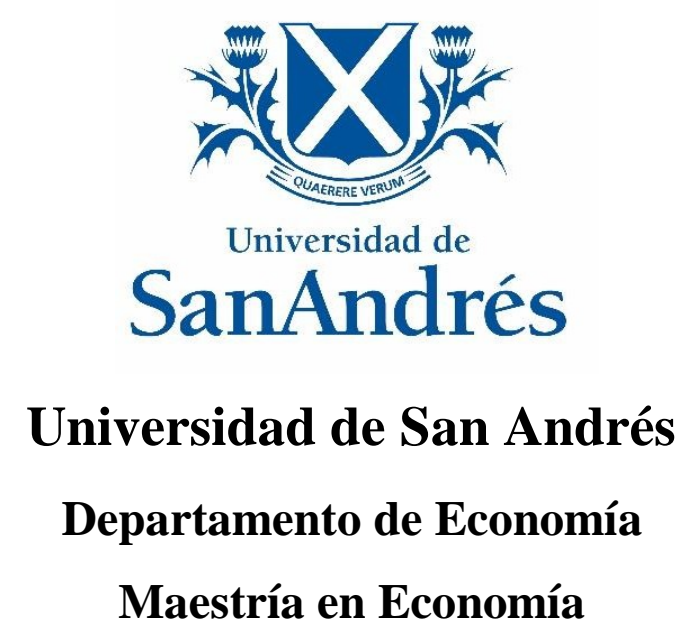

"Measuring the Effect of Policy on the Demand for Menthol Cigarettes: Evidence from Household Level Purchase Data”

\author{
Esteban PETRUZZELLO
}

30.666 .798

Mentor: Martín ROSSI

Victoria, Buenos Aires, Argentina

19 de septiembre, 2019 


\section{Tesis de Maestría en Economía de Esteban PETRUZZELLO}

\section{“Midiendo el efecto de las políticas públicas en la demanda de cigarrillos mentolados: evidencia basada en datos de compras de los hogares”}

\section{$\underline{\text { Resumen }}$}

En este trabajo utilizo datos de compras de los hogares para investigar el potencial impacto de una prohibición de los cigarrillos mentolados sobre distintas medidas de consumo de cigarrillos en comparación con políticas públicas tales como los impuestos y las restricciones públicas al cigarrillo. Los resultados muestran que los cigarrillos mentolados son menos adictivos que los tradicionales, y que la demanda por los mentolados es más inelástica. Las restricciones públicas al cigarrillo no son exitosas para reducir su consumo, aunque si reducen el consumo de cigarrillos tradicionales. Además, precios más altos no incrementan la probabilidad de dejar de fumar para los individuos que fuman mentolados. Estos hallazgos indican que las políticas públicas actuales no son efectivas para reducir el consumo de cigarrillos mentolados, y por ende puede ser necesaria su prohibición.

Palabras clave: Cigarrillos mentolados; adicción; dejar de fumar; restricciones púbicas al cigarrillo; impuestos a los cigarrillos

\section{"Measuring the Effect of Policy on the Demand for Menthol Cigarettes: Evidence from Household-Level Purchase Data”}

$\underline{\text { Abstract }}$

I use detailed household-level data to investigate the potential impact of a ban on menthol cigarettes on smoking when compared to intervention policies such as taxes and public smoking restrictions. The results show that menthols are less addictive than non-menthols, and that demand for menthol cigarettes is less price sensitive. Public smoking restrictions are unsuccessful in reducing menthol smoking, though they do reduce non-menthol consumption. Additionally, higher prices do not increase the likelihood of quitting for menthol smokers. These findings indicate that current policies are ineffective in curbing menthol smoking, and a complete ban might be required.

Keywords: Menthol cigarette; Addiction; Smoking cessation; Public smoking restriction; Cigarette tax Códigos JEL: D12, I18, L66 


\title{
Measuring the Effect of Policy on the Demand for Menthol Cigarettes: Evidence from Household Level Purchase Data
}

\author{
Esteban Petruzzello*
}

\begin{abstract}
I use detailed household-level data to investigate the potential impact of a ban on menthol cigarettes on smoking when compared to intervention policies such as taxes and public smoking restrictions. The results show that menthols are less addictive than non-menthols, and that demand for menthol cigarettes is less price sensitive. Public smoking restrictions are unsuccessful in reducing menthol smoking, though they do reduce non-menthol consumption. Additionally, higher prices do not increase the likelihood of quitting for menthol smokers. These findings indicate that current policies are ineffective in curbing menthol smoking, and a complete ban might be required.
\end{abstract}

Keywords: Menthol cigarette; Addiction; Smoking cessation; Public smoking restriction; Cigarette tax

JEL Codes: D12, I18, L66.

*A version of this paper was part of my $\mathrm{PhD}$ dissertation at Northwestern University and is forthcoming at the Eastern Economic Journal: Petruzzello, E. (2019) Measuring the Effect of Policy on the Demand for Menthol Cigarettes: Evidence from Household-Level Purchase Data, Eastern Economic Journal, 45(3), 422-445 https://doi.org/10.1057/s41302019-00139-2 


\section{INTRODUCTION}

Tobacco smoking is the leading cause of preventable death in the United States, killing nearly half a million Americans each year [Surgeon General's 2014 Report]. It is also responsible for substantial health-related economic losses, both in terms of medical cost and lost productivity [Xu et al. 2015]. Additionally, second-hand smoke causes severe health problems for those exposed to it [Surgeon General's 2014 Report]. Policies at all levels of government are constantly being implemented to address this public health issue. At the federal level, the 2009 Family Smoking Prevention and Tobacco Control Act gave the Food and Drug Administration (FDA) the power to regulate the manufacture, distribution, and marketing of tobacco products in order to protect public health [FDA Tobacco Control Act of 2009]. With this authority, the FDA has banned flavored tobacco products ${ }^{1}$ effective September 2009 (with the exception of menthol) and is currently considering a complete ban on menthols, which account for $30 \%$ of the cigarette market [FDA Flavored Tobacco Fact Sheet], about 4 billion packs at a prices ranging from $\$ 5$ to $\$ 10$ in 2017, around 25 billion dollars per year on average (CDC fact sheet). The Act did create the Tobacco Products Scientific Advisory Committee (TPSAC, established in 2010), which analyzes the impact of menthol cigarettes on public health.

In 2011, the TPSAC issued a report on the public health impact of menthol cigarettes. The document analyzed the population harm associated with the toxicity of the product, the intensity of its use, and its prevalence. The main conclusion of the report is that menthol cigarettes have a particularly adverse impact on public health in the U.S. and that their removal would be beneficial [TPSAC's Report 2011]. More specifically, the report states that it is biologically plausible that menthol makes cigarette smoking more addictive and that cessation is less likely to be successful among smokers of menthol cigarettes. Additionally, the report highlights the correlation between the availability of menthol cigarettes and regular smoking among youth and 
states that menthol cigarettes may contribute to the initiation and persistence of cigarette smoking as they may have a greater reinforcing effect. The FDA also received a document with the industry perspective on the public health impact of menthol cigarettes. That document states that there is no scientific basis to support the regulation of menthol cigarettes any differently than non-menthol cigarettes and that a ban on menthol cigarettes would result in significant countervailing effects, including a large illegal market with negative consequences for public health [The Industry Menthol Report 2011]. The FDA is currently reviewing all of the available evidence (the Committee's report and recommendation, the industry report, and reviews by external scientists) in its consideration of a potential ban. The Tobacco Control Act does not set a required deadline or timeline for the FDA to act on the recommendations provided by the Committee in the report. Some lawmakers have called on the FDA to ban menthols, New Jersey considered legislation banning menthols in early 2018, and the city of San Francisco has approved a menthol ban on May 2018. In November 2018, the FDA stated it will advance a Notice of Proposed Rulemaking that would seek to ban menthol in combustible tobacco products. $^{2}$

At the same time, various survey data suggest that menthol cigarettes may be intrinsically different from non-menthols. Some studies based on the Tobacco Use Supplements of the Current Population Survey have addressed the substitutability of menthol and non-menthol cigarettes. A question in the 2010 Tobacco Use Supplements of the Current Population Survey asked nearly 3,000 menthol smokers: "If menthol cigarettes were no longer sold, which of the following would you most likely do?" The answers: 39\% of menthol smokers said they would quit, 36\% said they would switch to non-menthol cigarettes, and $8 \%$ said they would switch to another tobacco product [Hartman 2011]. Tauras et al. [2010] examine previous Tobacco Use Supplements and report that smokers do not find menthol and non-menthol cigarettes to be close substitutes for one another. Moreover, they find that non-menthol cigarettes are less of a substitute for menthol cigarettes than vice versa. Levy et al. [2011] 
and Delnevo et al. [2011] analyze the same data and report that menthol smokers are more likely to make quitting attempts, but are less likely to quit.

This paper contributes to the policy debate by investigating the impact of intervention policies (taxes and public smoking restrictions) on menthol cigarette smoking in the light of a potential ban on menthol cigarettes being under consideration. I use detailed, high-frequency household level purchase data for the 2006-2010 period to estimate demand models that take into account the addictive nature of smoking. My baseline set-up consists of a cigarette demand model that captures one of the main features of addiction, reinforcement: greater past consumption of an addictive good raises current consumption. I also incorporate a second feature of addiction: the existence of withdrawal costs. When smokers' nicotine levels in a given period are zero (or substantially lower than the habitual levels), they can experience a physical discomfort that affects their purchase decisions. I analyze this cost by estimating a specification of the model that captures the effect of temporary smoking cessation on the purchases of the following period. The high frequency and richness of these panel data are crucial for the characterization of these underlying addiction dynamics.

I estimate the model for both menthol and non-menthol cigarettes and find the following results. First, demand for menthol cigarettes is less price sensitive than for non-menthols. On average, a price increase of one dollar reduces non-menthol consumption by about a pack per month, but only reduces menthol consumption by approximately half a pack. This suggests that public intervention in the form of higher cigarette taxes could be less successful at curbing menthol smoking. ${ }^{3}$ Second, menthol cigarettes are less addictive than non-menthols, as evidenced by the estimations of the two features of addiction. The reinforcement effect for non-menthols is $30 \%$ (for example, a pack smoked in the past month accounts for 0.3 packs smoked in the current one), while it is only $20 \%$ for menthols. Moreover, for non-menthol smokers, the withdrawal cost is responsible for the purchase of 0.8 packs on the month following the temporary cessation, while it is only 0.3 for menthol smokers. 
These estimations are addressing the addiction to nicotine; menthol smokers can also be addicted to the menthol flavor, and my results are consistent with this possibility that has been suggested by clinical psychologists.

Equipped with this basic framework, I then study the effectiveness of public smoking restrictions in curbing cigarette consumption. While these restrictions are primarily aimed at reducing exposure to second-hand smoke, they may also reduce the demand for cigarettes by creating an environment where smoking becomes increasingly more difficult (they increase the hassle cost associated with smoking) and also by shifting social norms. However, it could be the case that smokers maintain their cigarette consumption even in the presence of restrictions. My analysis takes advantage of the fact that there are states with no smoking restrictions during the 2006-2010 period and that the states that placed restrictions did so at different moments of time. This variability in time and space is exploited to identify the causal effect of smoking restrictions on cigarette purchases, controlling for time-invariant household characteristics and temporary shocks that are common across households. Specifically, households in states that lack smoking restrictions serve as controls for those in states that do have them. The results show that public smoking restrictions are ineffective in reducing menthol smoking. Notably, this is not the case for non-menthol cigarettes, as smoking restrictions reduce average non-menthol cigarette purchases by more than half a pack per month. ${ }^{4}$

Lastly, I examine the determinants of smoking cessation. I estimate a discrete-time hazard model of the probability of cessation that includes both time-invariant household characteristics and time-varying determinants, controlling for duration dependence. I find that higher prices are associated with a higher probability of quitting, but only for non-menthol smokers. I also find that smoking restrictions do not affect the likelihood of quitting. These findings, together with the results provided above, indicate that current policies are ineffective in curbing menthol smoking and suggest that if policy-makers continue to pursue an overall reduction in smoking of menthol cigarettes, a complete ban might be required, though other policies and regulations, such 
as advertisements, education, and risk-awareness, may also be helpful to curb menthol smoking.

The rest of the paper is organized as follows. The next section provides a brief description of the data and a descriptive analysis of the main variables. The Methodology and Results section introduces the baseline reinforcement model, discusses the differential impact of smoking restrictions, and presents the cessation model and results. The last two sections present additional findings, robustness checks, and the conclusion.

\section{DATA AND DESCRIPTIVE ANALYSIS}

The main data source for this paper is the Nielsen Homescan Data Set. This database contains a national panel of households that register their purchases of several product categories, including cigarettes, on a daily basis from 2006 to 2010. Households in this panel use a barcode scanner provided by Nielsen to input information about their purchases. Each record in the data shows the date and store where the transaction took place, how much was purchased of each product (universal product code level), and the price that was paid. There is also detailed information about product characteristics and household demographics ${ }^{5}$, both of which are updated annually.

If the transaction takes place at a store for which Nielsen already has store-level price data, Nielsen obtains the price directly from store data. If the store is not part of the Nielsen database, the household is asked to enter the price. Households have incentives provided by Nielsen to join the panel and remain active in reporting their transactions (such as monthly prize drawings and gift points). ${ }^{6}$ Einav et al. [2010] provide a quality check for these data by comparing them with data from cash registers. The authors conclude that the magnitude of the reporting error is similar to other commonly used databases.

It is important to emphasize that every cigarette transaction can be recorded, be it in a big chain store (like Walmart), a small tobacco shop, 
or a gas station. Even mail order, online shopping, and vending machines transactions are recorded. ${ }^{7}$ These data are quite unique and to the best of my knowledge there are only two papers (Harding et al. [2012] and Coti et al. [2016] that make use of these cigarette data.

There are 26,630 households that purchase cigarettes during the 20062010 period. Analyzing the total sample and the cigarette smokers subsample by year, I find that about $20 \%$ of the households make cigarette purchases, a number consistent with national figures. Data are observed at the household level; my baseline assumption is that there is only one smoker per household because this is by far the most frequent outcome in national surveys; about $60 \%$ of the households where someone smokes have only one smoker (National Health and Nutrition Examination Survey, 2011-2012). I explore alternative assumptions in the robustness checks section of this paper; the main results are the same for these alternative assumptions. ${ }^{8}$

Most of the households (about 80 percent) purchase only non-menthol cigarettes or only menthol cigarettes during the 2006-2010 period. Some of the households purchase both, but with a clear preference of one of the two types. Figure 1 shows the histogram for the quantity share of menthol cigarettes for each of the 26,630 households. For the purposes of this paper, a household is identified as menthol smoker if most of its cigarette expenditure is on menthols; the rest of the households are non-menthol smokers. ${ }^{9,10}$

[Figure 1 about here.]

Table 1 presents descriptive statistics. ${ }^{11}$ Column (1) of Table 1 shows information for the cigarette smokers sample. Columns (2) and (3) of Table 1 show the results splitting the sample between non-menthol smokers and menthol smokers.

[Table 1 about here.]

The main takeaway point of Table 1 is that there are no observable differences in characteristics between menthol and non-menthol smokers beyond 
the racial or ethnic minorities' preference towards menthols. The difference between average consumption levels is consistent with findings arising from survey data [Lawrence et al. 2010; Fagan et al. 2010]. Figure 2 presents the histograms of average packs smoked for each cigarette type, showing that the difference between average consumption levels is affected by the top of the distribution.

[Figure 2 about here.]

There is strong persistence in purchased brands; more than half of the households purchase only one brand and for about $80 \%$ of the households the top brand has a share higher than $70 \%$ of the total cigarette purchases. Additionally, cigarette purchases are very heterogeneous across households. The median monthly purchase in the sample is about two packs per month, while the 75th percentile is more than 10 packs; those figures are 16 and 32 packs respectively if we consider only the months with actual purchases.

For the purposes of this paper, I consider that purchases and consumption are equal at the month level. This is unlikely to cause interpretation problems for two reasons. First, cigarettes do not store well and are known to dry out and have a bad flavor after some weeks. Second, there is evidence that many smokers try to only purchase the amount they will consume in a relatively short time period as a way of exerting self-control. Having an excess stock of cigarettes could tempt the smoker into smoking more, thus many smokers opt for frequent, small purchases to regulate their consumption [Kim et al. 2006]. In my data, a household makes on average 2.7 cigarette transactions per month, while the median is about 2 transactions; these figures support the aggregation by month of purchase.

Data on the various increases in state cigarette excise taxes from 20062010 come from the Federation of American Tax Administrators. Information about county-level smoking restrictions comes from the Americans for Nonsmoker's Rights Foundation, while information about state-level restrictions comes from the Centers for Disease Control and Prevention. During the 2006- 
2010 period, several U.S. states (and the District of Columbia, which I treat as a state for the purposes of this paper) established smoking restrictions in public places such as bars, restaurants, and workplaces. Table 2 shows the timing of such restrictions.

[Table 2 about here.]

\section{METHODOLOGY AND RESULTS}

\section{Baseline Reinforcement Model}

I am interested in estimating the role of state dependence in demand for cigarettes. I do so by estimating the following equation:

$$
q_{i t}=\gamma \cdot p_{i t}+\beta \cdot q_{i, t-1}+\alpha_{i}+\mu_{t}+\epsilon_{i t}
$$

where $q_{i t}$ are the packs purchased by household $i$ in month $t ; p_{i t}$ is the average price per pack that was paid for that amount; $\alpha_{i}$ is household $i$ 's fixed effect; $\mu_{t}$ is a month-year effect common to all households; and $\epsilon_{i t}$ is the error term, assumed to be independent across households and serially uncorrelated (I address the validity of this assumption in the robustness checks section).

This equation is consistent with a boundedly-rational model of addiction in which individuals recognize the impact of past decisions but can only choose their current consumption based on current prices; Petruzzello [2019] confirms the validity of this assumption. In particular, households do not reduce their cigarette purchases before announced public smoking restrictions are established; they only do so once the restriction is in effect. ${ }^{12}$ State dependence is captured by adding a lag of the dependent variable as a regressor. I

analyze if, after controlling for time-invariant systematic differences (the $\alpha_{i}{ }^{\prime}$ s), the previous amount helps to explain the current one. More specifically, $\beta$ is a measure of the extent of reinforcement, one of the main features of addiction: the fact that greater past consumption of an addictive good raises current 
demand. Thus, if a good is addictive, we would expect $\beta$ to be positive; the degree of reinforcement is greater when the coefficient $\beta$ is larger.

Results for the estimation of Equation (1) are shown in Table 4. Columns (1) and (3) of Table 4 show the results of OLS fixed-effects estimation. There is a potential endogeneity bias that could arise from regressing the purchased packs of cigarettes on the price paid. ${ }^{13}$ Therefore, I also explore specifications in which I employ state excise taxes as instruments for the potentially endogenous prices. These sort of taxes are not established to counteract demand shocks, but to raise revenue [Adda and Cornaglia 2013]. Moreover, they heavily depend on state politics and legislative lags (varying widely across states and time). ${ }^{14}$ State excise taxes vary widely across states; for example, the excise tax in Missouri is $\$ 0.17$, while that figure is $\$ 4.35$ in New York (the median tax rate is $\$ 1.57) .{ }^{15,16}$ State taxes also vary through time; most of the states raise their cigarette excise taxes one or more times in the 2006-2010 period, and this is the key source of exogenous price variation. Gruber and Koszegi [2001] report that state tax increases are responsible for about $80 \%$ of the within state-year variation in prices. Table 3 shows all the excise tax increases, new rates, and date of application for any increase between January 2006 and December 2010. Table 5 shows first stage estimation results.

[Table 3 about here.]

[Table 4 about here.]

[Table 5 about here.]

Columns (2) and (4) of Table 4 show the results of 2SLS estimation. These results show that demand for menthol cigarettes is less price sensitive than for non-menthols. Moreover, demand for menthol cigarettes is very inelastic. On average, a price increase of one dollar reduces menthol consumption by less than a pack in the case of the 2SLS estimation, and by less than a 
tenth of a pack in the case of the OLS estimation; ${ }^{17}$ this last figure amounts to elasticities of -0.5 and -0.1 for nonmenthols and menthols respectively ${ }^{18}$. This suggests that public intervention in the form of higher cigarette taxes could be less successful to curb menthol smoking. The higher elasticities for non-menthol cigarettes are consistent with previous literature findings.

Additionally, menthol smoking displays a lower state dependence than non-menthol smoking: the reinforcement effect for non-menthol smoking is $27 \%$ (a pack smoked in the past month accounts for 0.27 packs smoked in the current one), while that figure is only $20 \%$ for menthol smoking. ${ }^{19}$ It is important to emphasize that the reinforcement coefficient in my specification aims to capture addiction related to nicotine intake. It could be the case that there is a separate addiction to the menthol flavor in cigarettes; this has been suggested by neuroscientists and clinical psychologists. ${ }^{20}$ In fact, many menthol smokers find that menthol-flavored cough drops or candy help them with quitting menthol cigarettes. Therefore, menthol smokers can be less addicted in terms of their nicotine component (which is captured by the reinforcement and withdrawal cost coefficients) while at the same time addicted to the menthol flavor (which would be controlled for by the household fixed effects, as this type of addiction is much less likely to be varying through the time frame of this study or according to consumption levels, since it is a preference for a flavor), and could therefore be more addictive than non-menthols overall. The distinction between the two types of addiction is very relevant in terms of policy because a potential ban on menthols would eliminate one of those two sources of addiction (barring black market considerations).

Lastly, it could be the case that households that smoke more purchase more inexpensive brands. If this is the case, the price coefficients will be biased. To address this concern, I estimate a variation of Equation (1) including brand fixed effects. Table 1 in the online appendix shows the results of the estimation; the main results are unchanged. ${ }^{21}$

Incorporating Withdrawal Costs. The specification I have explored 
incorporates one of the key components of addiction: reinforcement, the fact that past consumption of cigarettes increases current consumption. I also explore a specification that incorporates withdrawal costs. When the levels of nicotine in the body in a recent period are zero (or substantially lower than the habitual levels), there is a physical discomfort that affects the current decision. ${ }^{22}$ This effect is related to past cigarette consumption but is only triggered for individuals that try to reduce their consumption. Withdrawal costs have an asymmetric nature; they are not triggered by increases in consumption, only by reductions. As pointed out by Suranovic et al. [1999], the development of adjustment costs associated with cessation is sufficient to explain why smoking is habit-forming and is a critical element in making cigarettes addictive. ${ }^{23}$

I estimate a variation of the baseline model in which I include a withdrawal cost binary variable, $W_{i t}$. That variable is equal to 1 in period $t$ for household $i$ if that household purchased cigarettes on period $t-2$ but did not purchase cigarettes in $t-1$ (while still purchasing some other product in $t-1) .{ }^{24}$ If withdrawal costs were not a factor, we would expect that temporary cessation in the past month has no significant effect on current consumption, holding the rest of the variables fixed. ${ }^{25}$ Table 6 presents the results of the estimation, which show that the withdrawal cost coefficients are statistically and economically significantly different from zero. For non-menthol smokers, the withdrawal cost is responsible for an average of 0.8 packs on the month following the temporary cessation. This figure is only 0.3 packs for menthol smokers. Therefore, there is evidence of a lower impact of the withdrawal cost for menthol smokers. The rest of the results are very similar to the baseline estimations.

[Table 6 about here.]

\section{Differential Impact of Smoking Restrictions}

I now examine the effectiveness of public smoking restrictions in curbing smoking and analyze whether the impact is different for menthols and non-menthols. 
The main purpose behind the enactment of these types of restrictions is to reduce the exposure of non-smokers to secondhand smoke. Nonetheless, according to the World Health Organization, smoking restrictions may reduce the demand for cigarettes by creating an environment where smoking becomes increasingly more difficult and also by shifting social norms. By directly prohibiting smoking in certain areas, such restrictions may deter social smokers by eliminating common smoking settings. Additionally, these restrictions affect habitual smokers by increasing the hassle cost associated with smoking, as they must move out of restricted areas in order to smoke.

Evans et al. [1999] employ national surveys to estimate the effect of workplace smoking bans; they find that thise restrictions reduce smoking prevalence by 5 percentage points, and that they reduce daily consumtion among smokers by $10 \%$. Yurekli and Zhang [2000] find that anti-smoking laws have a significant negative effect of pre capita consumption of cigarettes. However, it could be the case that some smokers maintain their cigarette consumption even in the presence of restrictions. Adda and Cornaglia [2010] find some evidence that restrictions simply displace smoking to areas that are not restricted. Owyang and Vermann [2012] do not find correlation between smoking restrictions and smoking behavior examining survey data, while Irvine and Nguyen [2011] find that smoking restrictions have an effect on individuals at the top of the income distribution (they employ the 2003 Canadian Community Health Survey).

I benefit from the fact that there are states with no smoking restrictions during the 2006-2010 period and that the states that established restrictions did so at different moments of time. This variability is exploited to identify the causal effect of smoking restrictions on cigarette purchases, controlling for time-invariant household characteristics and temporary shocks that are common across households. Specifically, households in states that lack restrictions serve as controls for those in states that have a smoking restriction. ${ }^{26}$ I define the smoking restriction binary variable $B_{i t}$, which is equal to 1 in period $t$ for household $i$ if the state where the household resides established 
a smoking restriction on $t$ or before. Table 7 shows the results of incorporating this smoking restriction time-varying dummy on the specification of Equation (1) (Table 8 presents first stage results).

[Table 7 about here.]

[Table 8 about here.]

These results show that public smoking restrictions are inadequate to reduce menthol smoking. Notably, this is not the case for non-menthol cigarettes, as smoking restrictions reduce average non-menthol cigarette purchases by more than half a pack per month. Table 2 in the online appendix shows the results of incorporating brand fixed effects to the estimation; the main conclusions are the same. ${ }^{27}$

I also analyze the impact of the establishment of local smoking restrictions. The data identify the county where the purchasing household resides, though this information is only available for the years 2007, 2008, and 2009. There are 37 U.S. counties that establish a smoking restriction during this period. Table 3 in the online appendix shows the results of modifying the state-level restriction dummy to incorporate county-level restrictions. In the cases where there are both state- and county-level restrictions, the earliest was considered. The results are very similar to those on Table 7.

Examination of Household Heterogeneity. In order to examine the role of heterogeneity in addiction, I split the sample by minority status, median age, and median income per household member (also splitting the non-menthol and menthol smoker subsamples). I then estimate the baseline model with the state smoking restrictions dummy for each of those subsamples. ${ }^{28}$ Table 9 shows the estimations of the price effect, the reinforcement coefficient, and the impact of smoking restrictions for each subsample. We can see that the reinforcement coefficient for non-menthol smokers is smaller for younger households, which is consistent with the development of tolerance to nicotine as the person ages, and for wealthier households, which is consistent with financial 
stress being an important driver of smoking. This is also the case for menthol smokers, but the gaps are much smaller; this is consistent with the presence of a time-invariant addiction to the menthol flavor itself. The impact of smoking restrictions is significant for both minorities and non-minorities that smoke non-menthols. We can also see that the restrictions are effective for younger and wealthier households that smoke non-menthols. The price coefficient is not significant for younger, minority, and wealthier menthol smokers, while it is significant for their nonmenthol smoking counterparts. This is consistent with the baseline result: demand for menthols is less price sensitive than for nonmenthols, and very inelastic.

[Table 9 about here.]

\section{Differential Cessation and its Determinants}

More than half of the adult smoking population tried to quit smoking in 2010 [Behavioral Risk Factor Surveillance System Survey Data, 2011]. Although the health benefits are greater for people who stop at earlier ages, cessation has major health benefits at all ages [Centers for Disease Control and Prevention Fact Sheet, 2012]. Quitting is difficult and relapse rates are high; several attempts are usually required to stop smoking [Hughes et al. 2004; Herd et al. 2009].

I consider that households have ceased to smoke in month $t$ if they made their last cigarette purchase in month $t-1$ and have been otherwise active on the Nielsen panel for at least three more months after that last purchase $(t, t+1$, and $t+2)$. A rationale for the choice of three months as the minimum threshold is that it has been shown that it takes between 1.5-3 months after quitting before the number of nicotinic receptors in the brain of a smoker normalizes to non-smoker levels [Cosgrove et al. 2009]. Obviously, I have no way of confirming if this is in fact a permanent quitting situation, but this offers a reasonable approximation. According to this definition of quitting, $51 \%$ of the households in the sample make a potentially successful 
quitting attempt. This figure is virtually the same when comparing menthol and non-menthol smokers ( $51 \%$ and $50 \%$, respectively).

In order to analyze the determinants of quitting, I estimate a discretetime hazard logit model of the probability of cessation. This model presents both time-invariant household characteristics (minority status, age, and education level in 2006) and time-varying determinants in period $t$ (the establishment of state smoking restrictions, price, new births, and income), and it includes a sixth-degree time polynomial to control for duration dependence. ${ }^{29}$ The results are reported in Table 10.

[Table 10 about here.]

The likelihood of quitting is higher when income is higher and when following the birth of a child, as expected. We also see that younger smokers are more likely to quit. Education only increases the probability of quitting for non-menthol smokers. We also see that minority status is associated with a lower probability of cessation for menthol smokers and a higher one for non-menthol smokers; this is an interesting result since it has been suggested that menthol cigarettes have been targeted to minorities [TPSAC's Report, 2011]. In terms of smoking policy variables, higher prices are associated with a higher probability of quitting, but that effect is not significant for menthol smokers $^{30}$. Additionally, smoking restrictions do not have a significant impact on the probability of quitting for either type. ${ }^{31}$

\section{ROBUSTNESS CHECKS AND OTHER RE- SULTS}

\section{Households vs. Individuals}

Given that all of the observations are at the household level and not at the individual level, it is impossible to know how many smokers there are in households with more than one adult. The specifications I present assume that only 
one of the adults is a smoker in each household. To approach this issue, I perform two robustness checks. First, I replicate all of the main estimations over the subsample of households where there is only one adult (about a third of the total sample). Table 11 shows the results of the estimation; most of the qualitative results are the same as those in the full sample analysis. ${ }^{32}$

[Table 11 about here.]

A second robustness check employs the full sample and expands it. I assume that each of the $\mathrm{N}$ adults in the household smokes and that each of them smokes the same amount (a fraction $1 / N$ of the total). Here, every individual is represented in this expanded sample: individuals in one-adult households with exact information and individuals in other households with an assumption about their smoking. Once again, the qualitative results are mostly the same as in the original sample analysis. The main differences are: smaller price elasticities, a slightly smaller (but more statistically significant) impact of restrictions on consumption, and the restriction dummy coefficient becoming significant at $10 \%$ in the 2SLS specification of menthol smoking. ${ }^{33}$

\section{Dynamic Panels Issues}

I check the robustness of the main results to adding the packs purchased two months before to the estimation. Columns (1) and (4) of Table 12 show the results of estimating the baseline model by OLS when adding a second lag of the quantity as a regressor. Columns (2) and (5) show 2SLS results when taxes are used as instruments for the potentially endogenous price.

[Table 12 about here.]

The within transformation of the fixed effects estimator generates a transformed lagged dependent variable $\tilde{q}_{i, t-1}=q_{i, t-1}-\frac{1}{T-1} \sum_{\tau=1}^{T-1} q_{i \tau}$ and a transformed error term that is equal to $\tilde{\epsilon}_{i t}=\epsilon_{i t}-\frac{1}{T-1} \sum_{\tau=2}^{T} \epsilon_{i \tau}$. This implies a correlation between components of the two expressions. When the number 
of time periods is not small, as in this case, this correlation vanishes, and the fixed effects estimator is consistent [Alvarez and Arellano 2003]. Nonetheless, I address this concern by employing the Arellano and Bond [1991] GMM estimator, which employs levels of the lagged variables and first differences of the rest of the covariates as components of an instrument matrix. The values of purchased packs lagged two periods or more plus the first difference of the price are valid instruments in the equations in first differences. ${ }^{34}$ Columns (3) and (6) of Table 12 show the results, which are consistent with the previous estimates.

The Arellano-Bond procedure has another advantage in this context. One of the identifying assumptions is that the $\epsilon_{i t}$ 's are serially uncorrelated. This assumption can be tested by exploring whether there is second-order serial correlation in the first-differenced residuals [Arellano and Bond 1991]. I perform the Arellano-Bond test and find no evidence of such correlation, so there is no evidence of the employed moment conditions being invalid [Bond 2002].

\section{CONCLUSION}

Employing household level purchase data, I investigate the impact of intervention policies (taxes and public smoking restrictions) on menthol cigarette smoking in the light of a potential ban on menthol cigarettes being under consideration. I use the Nielsen Homescan Data Set, a national panel of households that register their purchases of cigarettes from 2006 to 2010, to estimate state dependence demand models. These models aim to capture the two main features of addiction: reinforcement (past consumption increases current consumption) and the existence of withdrawal costs upon temporary smoking cessation.

The results show that demand for menthol cigarettes is different than demand for non-menthols in a number of ways. First, demand for menthol 
cigarettes is less price sensitive than for non-menthols, which suggests that public intervention in the form of higher cigarette taxes could be less successful in curbing menthol smoking. Second, menthol cigarettes are less addictive than non-menthols. This effect has two sources corresponding to the two main features of addiction: a lower reinforcement effect and a smaller withdrawal cost effect. This is only referring to nicotine addiction; menthol smokers can have a separate addiction to the menthol flavor itself. Third, public smoking restrictions are not effective in reducing menthol smoking. Fourth, neither higher prices nor smoking restrictions increase the likelihood of quitting for menthol smokers. ${ }^{35}$.

These findings indicate that these current policies are unlikely to be very effective in curbing menthol smoking. If policy-makers continue to pursue an overall reduction in the smoking of menthol cigarettes, a complete ban might be required, though other policies and regulations, such as advertisements, education, and risk-awareness, may also be helpful to curb menthol smoking.

\section{ACKNOWLEDGEMENTS}

I would like to thank Aviv Nevo, Igal Hendel, and Robert Porter for their support and guidance. I would also like to thank German Bet, Ignacio Franceschelli, Frank Limbrock, Lee Lockwood, Fernando Luco, Guillermo Marshall, Cecilia Peluffo, Melissa Petruzzello, Tiago Pires, and Ana Reynoso for their valuable comments. This research was funded in part by a cooperative agreement between the USDA/ERS and Northwestern University, but the views expressed herein are those of the author and do not necessarily reflect the views of the U.S. Department of Agriculture. 


\section{Notes}

${ }^{1}$ While the ban on flavored cigarettes served to address the specific issue of preventing initiation in youth, its impact on the overall cigarette market was negligible.

${ }^{2}$ FDA Press Announcement, November 152018.

${ }^{3}$ Farrelly et al. [2004] and Coti et al. [2016], among others, find that higher cigarette taxes reduce cigarette purchases.

${ }^{4}$ Levy et al. [2004] and Gallus et al. [2006] provide evidence that smoking restrictions are generally effective to curb smoking; however, others (Adda and Cornaglia [2013] and Coti et al. [2016]) don't find them to be so effective.

${ }^{5}$ Maximum education level attained in the household; average age of adults on December 2005; minority dummy taking a value of zero if the respondent answered "White" and "No" to the "Race" and "Hispanic" entries respectively; mid-point of the corresponding annual household income interval; unemployment dummy equal to 1 if no household head is employed; and a new birth count variable. The time-varying household characteristics are income and new births, the rest are fixed.

${ }^{6}$ In order to preserve the quality of the data, Nielsen filters households that do not report their transactions regularly, and periodically adds new households to replace the ones who leave (trying to keep the sample demographics representative of national ones).

${ }^{7}$ Impersonal sales have been almost entirely prohibited since June 2010 (FDA Consumer Fact Sheet).

${ }^{8}$ The Tobacco Use Supplement reported individual prevalence is $15.5 \%$ for women and $20.1 \%$ for men in 2006-2007; those figures are $14.2 \%$ and $18 \%$ in the following wave (20102011).

${ }^{9} \mathrm{I}$ also explore the results of an alternative definition in which a household is identified as menthol smoker if its expenditure on menthol cigarettes more than doubles the expenditure of non-menthol cigarettes; none of the main conclusions are altered with this approach.

${ }^{10} \mathrm{I}$ analyze the purchasing behavior of about 200 households that acquire substantial quantities of both menthols and non-menthols between 2006 and 2010; their purchasing patterns are consistent with two different adults smoking, one flavor each (as opposed to one person smoking both types interchangeably). These households and some others are dropped in the robustness checks I performed and the results are the same.

${ }^{11}$ Detailed descriptions of the variables can be found in the Appendix. I aggregate data by month of purchase and weight prices according to the purchased volume. Therefore, a data point is a household-month observation, and the price variable is the average price paid by the household during that month. The panel is unbalanced, but the median time a household stays on the cigarette smokers sample in the data is 36 months. Also, all the 
products are standardized at the level of a pack (20 cigarettes), with a cigarette length of $85 \mathrm{~mm}$ (known as King size).

${ }^{12}$ An alternative approach would be to include a lead of the dependent variable; this would be consistent with the standard rational addiction model specification, which relies on forward-looking behavior.

${ }^{13}$ The concern is associated to potential shocks to demand at the state level; this has been discussed in Adda and Cornaglia [2013] and Abrevaya and Puzzello [2012].

${ }^{14}$ Cigarette excise taxes have been employed as an instrument for cigarette prices in similar contexts [Becker et al. 1994; Gruber et al. 2003; Adda and Cornaglia 2013].

${ }^{15}$ Very few counties and cities in the U.S. establish their own excise taxes. Cook County (IL) has a large cigarette tax (about $\$ 2$ during the analyzed period); however, it is the only US county with such a large tax. The second highest would be Cuyahoga County $(\mathrm{OH})$ with a $\$ 0.345$ tax. Very few other states have county-level taxes, and those are very small. Including these taxes into the analysis yields the same conclusions, which is reasonable since those represent very few observations overall. Some cities have their own excise taxes; however, I do not have a way to identify the city of the panelist, only the county, and only for the 2007-2009 period.

${ }^{16}$ The federal tax rate had been $\$ 0.39$ since 2002 until April 2009, when it was raised to $\$ 1.01$ to provide funding for the 2009 expansion of the Children's Health Insurance Program.

${ }^{17}$ The differences between the OLS and 2SLS price coefficients can be attributed to measurement error in the price variable (due, for example, to the necessary aggregation at the month level) and the existence of unobserved promotional activities that affect the level of consumption and could be correlated with prices. It is also the case that not all of the states have cigarette tax increases; the instrument is therefore capturing the reaction of a subset of an heterogeneous population. If the sample is restricted to the observations in states/years in which there are tax increases in the state, the OLS coefficients are much closer to the 2SLS ones

${ }^{18}$ These figures are for the elasticities evaluated at the average; the average elasticities are -0.6 and -0.1 for non-menthols and menthols, respectively, in the case of the OLS estimation; these average elasticities are -1.8 and -1.2 in the case of the 2SLS estimation.

${ }^{19} \mathrm{I}$ also estimate specifications that include a lag of the price variable in order to control for recent price changes that could have an impact in the quantity purchased (thus affecting the estimation of the state dependence coefficient). The main results are the same as in the specification shown; in particular, the state dependence coefficients are very close to the ones estimated in the baseline model.

${ }^{20}$ Ahijevych and Garrett [2004; 2010], Wickham [2015], and Thompson et al. [2017] address this issue. 
${ }^{21} \mathrm{I}$ have also estimated a fixed-effects Poisson model to address the nature of the dependent variable (packs purchased per month); the qualitative results are the same.

${ }^{22}$ These effects have been widely documented; Harris [1993] provides a summary.

23 "An addiction is the compulsive need for and use of a habit-forming substance characterized by tolerance and by well-defined physiological symptoms upon withdrawal" (MerriamWebster dictionary).

${ }^{24}$ For this specification it is crucial to consider the months with no cigarette purchases. To define a price for the months with no purchases, I assign the last price paid and update this value with any increase in state or federal taxes if applicable.

${ }^{25}$ The subsection on smoking cessation presents a discussion about the choice of a month as the relevant unit of measurement for withdrawal cost purposes.

${ }^{26}$ Trends in smoking rates before restrictions are imposed for states that will impose them and for states that will not do not display significant differences; additionally, I estimated a discrete-time hazard model of the probability of establishing a restriction; observable timevarying shocks are not correlated with the decision to establish a restriction (results available in Table 4 in the online appendix).

${ }^{27} \mathrm{I}$ also compute standard errors clustered at the state level due to a potential concern of serial correlation in the error term within states. The results of this and previous specifications are unaffected; in particular, the effect of smoking restrictions on non-menthol consumption is still statistically significant.

${ }^{28}$ The coefficients from Table 9 correspond to 2SLS estimation.

${ }^{29}$ For this model I need to define the price for the quitting month and for previous months when there were no purchases of cigarettes but the household was active in some other category. For those months I assign the last price paid and I update this value with any increase in state or federal taxes if applicable.

${ }^{30}$ Wickman [2015] reports that "menthol's salient sensory properties (...) may explain why menthol smokers have a harder time quitting than non-menthol smokers."

${ }^{31}$ I also analyzed a specification that controls for prices and public smoking restrictions in $t-1$ and also the changes between $t-1$ and $t$; results are reported in Table 5 in the online appendix; the conclusions are similar.

${ }^{32}$ The main differences are that the price variable becomes insignificant for non-menthol smokers in the specification estimated by 2SLS. Also, the new birth variable and some of the time-invariant covariates become insignificant for the quitting hazard.

${ }^{33}$ Another difference is that price and smoking restrictions become significant in the quitting hazard for menthol smoking, but this result is not robust to the menthol smoker alternative specification.

${ }^{34}$ This relies on the errors being serially uncorrelated; this is discussed on the next para- 
graph.

${ }^{35} \mathrm{It}$ is of course possible that these restrictions are effective at reducing smoking rates through prevention; unfortunately I cannot address the issue of prevention due to the nature of the Nielsen dataset. 


\section{References}

[1] ABREvayA, J. and PUZELlO, L. 2012:" Taxes, Cigarette Consumption, and Smoking Intensity: Comment, American Economic Review, 102(4): 1751-63.

[2] ADDA, J. and CORNAGLIA, F. 2010: The Effect of Bans and Taxes on Passive Smoking, American Economic Journal: Applied Economics, 2: 1-32.

[3] ADDA, J. and CORNAGLIA, F. 2013: Taxes, Cigarette Consumption, and Smoking Intensity: Reply, American Economic Review, 103, 3102-3114.

[4] AHIJEVYCH, K. and GARRETT, B.E. 2004: Menthol Pharmacology and Its Potential Impact of Cigarette Behavior, Nicotine and Tobacco Research, 6, S1728.

[5] AHIJEVYCH, K. and GARRETT, B.E. 2010: The Role of Menthol in Cigarettes as a Reinforcer of Smoking Behavior, Nicotine and Tobacco Research, 12, S110-116.

[6] AlVAREZ, J. and ARELlanO, M. 2003: The Time Series and Cross-Section Asymptotics of Dynamic Panel Data Estimators, Econometrica, 71, 1121-1159.

[7] ARELlano, M. and BOND, S. 1991: Some Tests of Specification for Panel Data: Monte Carlo Evidence and an Application to Employment Equations, Review of Economic Studies, 58, 277-297.

[8] BECKER, G., GROSSMAN, M., and MURPHY, K. 1994: An Empirical Analysis of Cigarette Addiction, American Economic Review, 84, 396-418.

[9] BECKER, G. and MURPHY, K. 1988: A Theory of Rational Addiction, Journal of Political Economy, 96, 675-700.

[10] Behavioral Risk Factor Surveillance System Survey Data, 2011.

[11] BOND, S. Dynamic Panel Data Models: A Guide to Micro Data Methods and Practice The Institute for Fiscal Studies, Department of Economics, UCL cemmap working paper CWP09/2002

[12] Centers for Disease Control and Prevention Fact Sheet, 2012. 
[13] CHALOUPKA, F.J. 1991: Rational Addictive Behavior and Cigarette Smoking, Journal of Political Economy, 99, 722-42.

[14] COSGROVE, K.P., BATIS, J., BOIS, F., MACIEJEWSKI, P.K., ESTERLIS, I., KLOCZYNSKI, T., STIKLUS, S., KRISHNAN-SARIN, S., O'MALLEY, S., PERRY, E., TAMAGNAN, G., SEIBYL, J.P., and STALEY, J.K. 2009: Beta2*-Nicotinic Acetylcholine Receptor Availability during Acute and Prolonged Abstinence from Tobacco Smoking Archives of General Psychiatry, 66, 666-676.

[15] COTTI, C., NESSON, E., TEFFT, N. 2016: The Effects of Tobacco Control Policies on Tobacco Products, Tar, and Nicotine Purchases among Adults: Evidence from Household Panel Data American Economic Journal: Economic Policy, 8(4): 103-123.

[16] DELnEVO, C.D., GUNDERSEN, D.A., and HRWYNA, M. 2010: Examining the Relationship Between Menthol Smoking and Cessation Using Data from the 2003 and 2006/7 Tobacco Use Supplement, submission to the U.S. Food and Drug Administration.

[17] EINAV, L., LEIBTAG, E., and NEVO, A. 2010: Recording Discrepancies in Nielsen Homescan Data: Are They Present and Do They Matter? Quantitative Marketing and Economics, 8, 207-239.

[18] EVAnS, W., FARRELlY, M., and MONTGOMERY, E. 1999: Do Workplace Smoking Bans Reduce Smoking? American Economic Review, 89(4), 728-747.

[19] FAgan, P., MoOlchan, E.T., HART, A., ROSE, A., LAWREnCE, D., SHAVERS, V.L., and GIBSON, J.T. 2010: Nicotine Dependence and Quitting Behaviors among Menthol and Non-Menthol Smokers with Similar Consumption Patterns Addiction, 105, 55-74.

[20] FARRELLY, M., NIMSCH, C., HYLAND, A., and CUMMINGS, M. 2004: The effects of higher cigarette prices on tar and nicotine consumption in a cohort of adult smokers, Health Economics, 13(1): 4958.

[21] Food and Drug Administration, Flavored Tobacco Fact Sheet, 2009. 
[22] Food and Drug Administration, Tobacco Control Act 2009.

[23] GAllus, S., ZUCCARO, P., COlOMBO, P., APOlOnE, G., PACIFICI, R., GARATTINI, S., and LA VECCHIA, C. 2006: Effects of new smoking regulations in Italy, Annals of Oncology, 17(2):346347.

[24] GRUBER, J. and KOSZEGI, B. 2001: Is Addiction "Rational"? Theory and Evidence, Quarterly Journal of Economics, 116, 1261-303.

[25] GRUBER, J., SEN, A., and STABILE, M. 2003: Estimating Price Elasticities When There Is Smuggling: The Sensitivity of Smoking to Price in Canada Journal of Health Economics, 22, 821-842.

[26] GUL, F. and PESENDORFER, W. 2007: Harmful Addiction, Review of Economic Studies, 74, 147-172.

[27] HARDING, M., LEIBTAG, E., and LOVENHEIM, M.F. 2012: The Heterogeneous Geographic and Socioeconomic Incidence of Cigarette Taxes: Evidence from Nielsen Homescan Data, American Economic Journal: Economic Policy, 4, 169-198.

[28] HARRIS, J. 1993: Deadly Choices: Coping with Health Risks in Everyday Life. Basic Books, New York.

[29] HARTMAN, A.M. 2011: What Menthol Smokers Report They Would Do If Menthol Cigarettes Were No Longer Sold, Presentation to the FDA Tobacco Products Scientific Advisory Committee Meeting.

[30] HERD, N., BORLAND, R., and HYLAND, A. 2009: Predictors of smoking relapse by duration of abstinence: findings from the International Tobacco Control (ITC) Four Country Survey, Addiction, 104(12):2088-2099.

[31] HUGHES, J.R., KEELY, J., and NAUD, S. 2004: Shape of the relapse curve and long-term abstinence among untreated smokers, Addiction, 99, 2938.

[32] IRVINE, I.J. and NGUYEN, H.V. 2011: Toxic Choices: The Theory and Impact of Smoking Bans, Forum for Health Economics and Policy, 14. 
[33] KEELER, T.E., HU, T-W., BARNETT, P.G., and MANNING, W.G. 1993: Taxation, Regulation, and Addiction: A Demand Function for Cigarettes Based on Time-Series Evidence, Journal of Health Economics, 12, 1-18.

[34] KIM, A.E., RIBISL, K.M., DELNEVO, C.D., and HRYWNA, M. 2006: Smokers' Beliefs and Attitudes about Purchasing Cigarettes on the Internet Public Health Rep., 121, 594-602.

[35] LAWrence, D., ROSE, A., FAGAN, P., MOOlChAn, E.T., GIBSON, J.T., and BACKINGER, C.L. 2010: National Patterns and Correlates of Mentholated Cigarette Use in the United States Addiction, 105, 13-31.

[36] LEVY, D.T., BLACKMAN, K., TAURAS, J., CHAlOUPKA, F.J., VILLANTI, A., and NIAURA, R.S. 2011: Quit Attempts and Quit Rates among Menthol and Non-Menthol Smokers in the United States, American Journal of Public Health, 101, 1241-1247.

[37] LEVY, D., CHALOUPKA, F., and GITCHELL,J. 2004: The Effects of Tobacco Control Policies on Smoking Rates: A Tobacco Control Scorecard Journal of Public Health Management and Practice, 10(4)338353.

[38] National Health and Nutrition Examination Survey (2011-2012)

[39] OWYANG, M.T. and VERMANN, E.K. 2012: Where There's a Smoking Ban, There's Still Fire, Federal Reserve Bank of St. Louis Review, 94, 265-86.

[40] PETRUZZELLO, E. 2019: Testing for Forward-Looking Behaviour: Evidence from the Enactment of Smoking Restrictions, Applied Economics, 51:19, 20612069, DOI: 10.1080/00036846.2018.1540845

[41] PETRUZZELLO, E. (2019) Measuring the Effect of Policy on the Demand for Menthol Cigarettes: Evidence from Household-Level Purchase Data, Eastern Economic Journal, 45(3), 422-445 https://doi.org/10.1057/s41302-019-00139-2

[42] Surgeon General's Report 2014.

[43] SURANOVIC, S.M., GOLDFARB, R.S., and LEONARD, T.C. 1999: An Economic Theory of Cigarette Addiction Journal of Health Economics, 18, 1-29. 
[44] The Industry Menthol Report 2001: Menthol Cigarettes: No Disproportionate Impact on Public Health.

[45] TAURAS, J.A., LEVY, D.T, CHALOUPKA, F.J., VILLANTI, A., NIAURA, R.S., VALLONE, D., and ABRAMS, D.B. 2010: Menthol and Non-menthol Smoking: the Impact of Prices and Smoke-Free Air Laws, Addiction, 105, 115123.

[46] Tobacco Products Scientific Advisory Committee 2011: Menthol Cigarettes and Public Health: Review of the Scientific Evidence and Recommendations.

[47] U.S. Census Bureau, Current Population Survey, 2010.

[48] WICKHAM, R. J. 2015: How Menthol Alters Tobacco-Smoking Behavior: A Biological Perspective The Yale journal of biology and medicine, 88(3), 279-87.

[49] XU, X., BISHOP, E., KENNEDY, S., SIMPSON, S., and PECHACEK, T. 2014: Annual Healthcare Spending Attributable to Cigarette Smoking: An Update, American Journal of Preventive Medicine,48(3), 326333.

[50] YUREKLI, A. and ZHANG, P. 2000: The impact of clean indoor-air laws and cigarette smuggling on demand for cigarettes: an empirical model, Health Economics, 9, 159-170. 


\section{Appendix: Description of the variables}

- College dummy: 1 if maximum education level attained in the household is any college attendance. This includes "Some College," "Graduated College," and "Post College Grad."

- Age: Age on December 2005 (if more than one adult, average age).

- Minority dummy: 0 if the respondent answered "White" and "No" to the "Race" and "Hispanic" entries, respectively.

- Income: Mid-point of the corresponding annual income interval (annual income is categorized in 17 brackets between $\$ 5,000$ and $\$ 200,000)$.

- Unemployed or Retired: 1 if no household head is employed.

- Births: Births $s_{i t}$ is equal to 1 if there was a birth in household $i$ on month $t$ or before, but after January 2006; and is equal to 2 if there was a second birth in household $i$ on month $t$ or before, but after January 2006. It takes the value zero otherwise. 
Figure 1: Histogram of the quantity share of menthol cigarettes

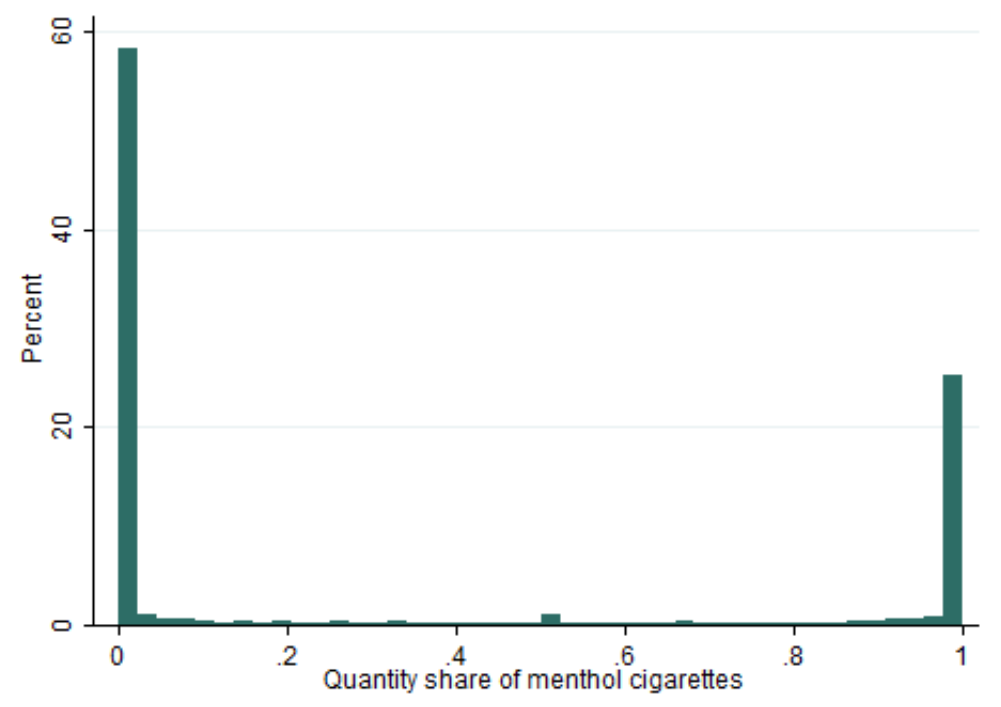

Source: Nielsen Homescan data. 
Figure 2: Histograms of average packs smoked by cigarette type

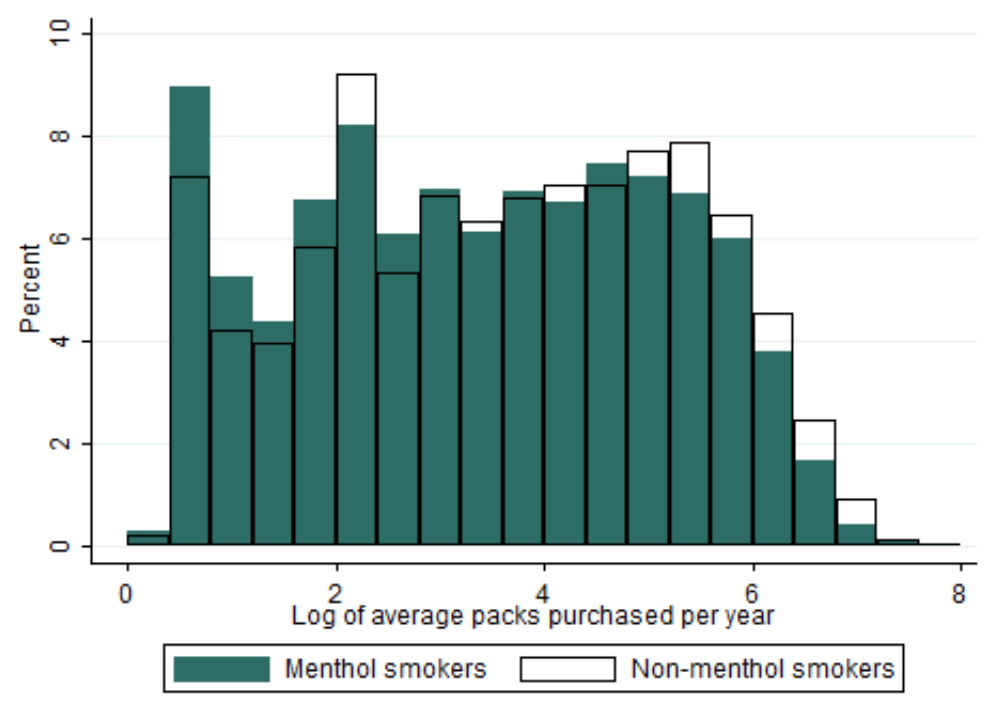

Source: Nielsen Homescan data. 
Table 1: Descriptive statistics

\begin{tabular}{l|ccc}
\hline \hline & All & Non-menthol smokers & Menthol smokers \\
\hline Number of Households & 26,630 & 17,794 & 8,836 \\
Income & $\$ 51,894$ & $\$ 51,561$ & $\$ 52,566$ \\
Household Size & 2.5 & 2.5 & 2.5 \\
Income per HH Member & $\$ 24,387$ & $\$ 24,121$ & $\$ 24,923$ \\
Age & 49.9 & 49.8 & 50.2 \\
Minority & $18.3 \%$ & $13.5 \%$ & $27.9 \%$ \\
Some College & $74.0 \%$ & $73.0 \%$ & $76.0 \%$ \\
Unemployed or Retired & $24.3 \%$ & $24.5 \%$ & $24.0 \%$ \\
Packs per Month & 8.3 & 8.9 & 7.0 \\
Price per Pack & $\$ 3.8$ & $\$ 3.8$ & $\$ 3.8$ \\
\hline
\end{tabular}

Source: Nielsen Homescan data. Averages across all time periods. 
Table 2: List of state smoking restrictions, 2006-2010

\begin{tabular}{ccl||cll}
\hline \hline Month & Year & State & Month & Year & State \\
\hline Apr & 2006 & New Jersey & Oct & 2007 & Minnesota \\
Jul & 2006 & Arkansas & Jan & 2008 & Illinois \\
Jul & 2006 & Colorado & Feb & 2008 & Maryland \\
Nov & 2006 & Hawaii & Jul & 2008 & Iowa \\
Nov & 2006 & Nevada & Sep & 2008 & Pennsylvania \\
Dec & 2006 & Ohio & Jan & 2009 & Oregon \\
Jan & 2007 & Dist. of Columbia & Jun & 2009 & Nebraska \\
Jan & 2007 & Louisiana & Nov & 2009 & South Dakota \\
Jan & 2007 & Utah & Dec & 2009 & Virginia \\
May & 2007 & Arizona & Jan & 2010 & North Carolina \\
Jun & 2007 & New Mexico & May & 2010 & Michigan \\
Jul & 2007 & Tennessee & Jul & 2010 & Kansas \\
Sep & 2007 & New Hampshire & Jul & 2010 & Wisconsin \\
\hline
\end{tabular}

Source: Centers for Disease Control and Prevention. There are fourteen states with smoking restrictions established before 2006: California, Delaware, Connecticut, Florida, Idaho, New York, Maine, Massachusetts, Georgia, Montana, North Dakota, Rhode Island, Vermont, and Washington. The state of Indiana established a restriction on 2012. The remaining ten states have no statewide smoking restriction as of September 2014: Alabama, Alaska, Kentucky, Mississippi, Missouri, Oklahoma, South Carolina, Texas, West Virginia, and Wyoming. 
Table 3: Excise tax increases, rates, and date of application

\begin{tabular}{clcc||clcc}
\hline \hline Date & State & Raise & New Rate & Date & State & Raise & New Rate \\
\hline $07 / 01 / 06$ & Alaska & 0.20 & 1.80 & $04 / 01 / 09$ & U.S. (fed. rate) & 0.62 & 1.01 \\
$07 / 01 / 06$ & N. Jersey & 0.18 & 2.58 & $04 / 10 / 09$ & Rhode Island & 1.00 & 3.46 \\
$07 / 01 / 06$ & N. Carolina & 0.05 & 0.35 & $05 / 15 / 09$ & Mississippi & 0.50 & 0.68 \\
$09 / 30 / 06$ & Hawaii & 0.20 & 1.60 & $07 / 01 / 09$ & Delaware & 0.45 & 1.60 \\
$12 / 07 / 06$ & Arizona & 0.82 & 2.00 & $07 / 01 / 09$ & Florida & 1.00 & 1.33 \\
$01 / 01 / 07$ & S. Dakota & 1.00 & 1.53 & $07 / 01 / 09$ & Hawaii & 0.60 & 2.60 \\
$01 / 01 / 07$ & Texas & 1.00 & 1.41 & $07 / 01 / 09$ & Kentucky & 0.30 & 0.60 \\
$03 / 01 / 07$ & Iowa & 1.00 & 1.36 & $07 / 01 / 09$ & N. Hampshire & 0.70 & 1.78 \\
$07 / 01 / 07$ & Alaska & 0.20 & 2.00 & $07 / 01 / 09$ & N. Jersey & 0.13 & 2.70 \\
$07 / 01 / 07$ & Connecticut & 0.49 & 2.00 & $07 / 01 / 09$ & Vermont & 0.45 & 2.24 \\
$07 / 01 / 07$ & Indiana & 0.44 & 1.00 & $07 / 01 / 09$ & Wisconsin & 0.75 & 2.52 \\
$07 / 01 / 07$ & N. Hampshire & 0.28 & 1.08 & $09 / 01 / 09$ & N. Carolina & 0.10 & 0.45 \\
$07 / 01 / 07$ & Tennessee & 0.42 & 0.62 & $10 / 01 / 09$ & Connecticut & 1.00 & 3.00 \\
$08 / 01 / 07$ & Delaware & 0.60 & 1.15 & $10 / 01 / 09$ & Dist. of Columbia & 1.50 & 2.50 \\
$09 / 30 / 07$ & Hawaii & 0.20 & 1.80 & $11 / 01 / 09$ & Pennsylvania & 0.25 & 1.60 \\
$01 / 01 / 08$ & Maryland & 1.00 & 2.00 & $05 / 01 / 10$ & Washington & 1.00 & 3.03 \\
$01 / 01 / 08$ & Wisconsin & 1.00 & 1.77 & $07 / 01 / 10$ & Hawaii & 0.40 & 3.00 \\
$06 / 03 / 08$ & N. York & 1.25 & 2.75 & $07 / 01 / 10$ & New Mexico & 0.75 & 1.66 \\
$07 / 01 / 08$ & Massachusetts & 1.00 & 2.51 & $07 / 01 / 10$ & New York & 1.60 & 4.35 \\
$09 / 30 / 08$ & Hawaii & 0.20 & 2.00 & $07 / 01 / 10$ & S. Carolina & 0.50 & 0.57 \\
$03 / 01 / 09$ & Arkansas & 0.56 & 1.15 & $07 / 01 / 10$ & Utah & 1.01 & 1.70 \\
\hline
\end{tabular}

Source: Federation of American Tax Administrators. 
Table 4: Estimation of the baseline model

\begin{tabular}{c|cccc}
\hline \hline & \multicolumn{4}{|c}{ Dep. variable: packs purchased per month } \\
\hline & \multicolumn{2}{|c}{ Non-menthol } & \multicolumn{3}{c}{ Menthol } \\
\hline \multirow{2}{*}{ Price } & $(1)$ & $(2)$ & $(3)$ & $(4)$ \\
& OLS & 2SLS & OLS & 2SLS \\
& $\left(0.6574^{* * *}\right.$ & $-1.2174^{* * *}$ & $-0.0727^{* * *}$ & $-0.9942^{* * *}$ \\
& & $(0.2565)$ & $(0.0104)$ & $(0.2954)$ \\
Packs & $0.2693^{* * *}$ & $0.2676^{* * *}$ & $0.2006^{* * *}$ & $0.1963^{* * *}$ \\
t-1 & $(0.0152)$ & $(0.0153)$ & $(0.0073)$ & $(0.0074)$ \\
& & & & \\
\hline F-stat & & 1103.47 & 322.17 \\
$\mathrm{R}^{2}$ & 0.6765 & 0.1003 & 0.1068 \\
$\mathrm{~N}$ & 214234 & 209202 & 108607 & 104664 \\
\hline
\end{tabular}

Robust standard errors are in parenthesis. All the regressions include month dummies and household fixed effects. Columns (1) and (3) show the results of OLS estimation, while Columns (2) and (4) present 2SLS estimation results. The R squared reported for 2SLS estimations is the within R squared. F-stat is the statistic for the first-stage $\mathrm{F}$ test of excluded instruments. ${ }^{*}$ Statistically different from 0 at $10 \%$ significance; ${ }^{* *}$ Statistically different from 0 at $5 \%$ significance; ${ }^{* * *}$ Statistically different from 0 at $1 \%$ significance. 
Table 5: Baseline model - First stage results

\begin{tabular}{c|cc}
\hline \hline & \multicolumn{2}{|c}{ Dep. variable: price paid } \\
\hline & Non-menthol & Menthol \\
\hline & $(1)$ & $(2)$ \\
\hline Tax rate & $0.6843^{* * *}$ & $0.6845^{* * *}$ \\
& $(0.0206)$ & $(0.0381)$ \\
\hline F-stat & 1103.47 & 322.17 \\
$\chi^{2}$-stat & 4.64 & 9.82 \\
$\mathrm{R}^{2}$ & 0.1025 & 0.0110 \\
$\mathrm{~N}$ & 209202 & 104664
\end{tabular}

Robust standard errors are in parenthesis. All the regressions include month dummies and the lagged quantity. F-stat is the statistic for the first-stage $\mathrm{F}$ test of excluded instruments. ${ }^{* * *}$ Statistically different from 0 at $1 \%$ significance. 
Table 6: Estimation of the baseline model with withdrawal costs

\begin{tabular}{|c|c|c|c|c|}
\hline & \multicolumn{4}{|c|}{ Dep. variable: packs purchased per month } \\
\hline & \multicolumn{2}{|c|}{ Non-menthol } & \multicolumn{2}{|c|}{ Menthol } \\
\hline & (1) & $(2)$ & $(3)$ & $(4)$ \\
\hline & OLS & 2SLS & OLS & 2SLS \\
\hline Withdrawal & $0.8085^{* * *}$ & $0.8208^{* * *}$ & $0.3174^{* * *}$ & $0.2567^{* *}$ \\
\hline cost effect & $(0.1089)$ & $(0.1098)$ & $(0.0949)$ & $(0.1059)$ \\
\hline Price & $-0.2381^{* * *}$ & $-1.0489^{* * *}$ & $-0.0386^{* * *}$ & $-0.9149^{* * *}$ \\
\hline & $(0.0544)$ & $(0.1033)$ & $(0.0045)$ & $(0.1463)$ \\
\hline Packs & $0.3365^{* * *}$ & $0.3337^{* * *}$ & $0.2917^{* * *}$ & $0.2839^{* * *}$ \\
\hline t-1 & $(0.0105)$ & $(0.0106)$ & $(0.0085)$ & $(0.0087)$ \\
\hline F-stat & & 6441.57 & & 867.30 \\
\hline $\mathrm{R}^{2}$ & 0.6701 & 0.1408 & 0.6687 & 0.0641 \\
\hline $\mathrm{N}$ & 478376 & 478226 & 235298 & 235192 \\
\hline
\end{tabular}

Robust standard errors are in parenthesis. All the regressions include month dummies and household fixed effects. Columns (1) and (3) show the results of OLS estimation, while Columns (2) and (4) present 2SLS estimation results. The R squared reported for 2SLS estimations is the within R squared. F-stat is the statistic for the first-stage $\mathrm{F}$ test of excluded instruments. ${ }^{*}$ Statistically different from 0 at $10 \%$ significance; ${ }^{* *}$ Statistically different from 0 at $5 \%$ significance; ${ }^{* * *}$ Statistically different from 0 at $1 \%$ significance. 
Table 7: Impact of state smoking restrictions

\begin{tabular}{|c|c|c|c|c|}
\hline & \multicolumn{4}{|c|}{ Dep. variable: packs purchased per month } \\
\hline & \multicolumn{2}{|c|}{ Non-menthol } & \multicolumn{2}{|c|}{ Menthol } \\
\hline & (1) & $(2)$ & $(3)$ & (4) \\
\hline & OLS & 2SLS & OLS & 2SLS \\
\hline Smoking & $-0.5548^{* * *}$ & $-0.5021^{* *}$ & -0.0523 & -0.3686 \\
\hline restriction & $(0.2070)$ & $(0.2031)$ & $(0.2133)$ & $(0.2503)$ \\
\hline Price & $-0.6985^{* * *}$ & $-1.6607^{* * *}$ & $-0.0602^{* * *}$ & $-1.3486^{* * *}$ \\
\hline & $(0.0670)$ & $(0.4273)$ & $(0.0082)$ & $(0.4395)$ \\
\hline Packs & $0.2977^{* * *}$ & $0.2956^{* * *}$ & $0.2214^{* * *}$ & $0.2147^{* * *}$ \\
\hline $\mathrm{t}-1$ & $(0.0190)$ & $(0.0192)$ & $(0.0086)$ & $(0.0091)$ \\
\hline F-stat & & 1791.88 & & 73.35 \\
\hline $\mathrm{R}^{2}$ & 0.6689 & 0.1112 & 0.6844 & 0.3462 \\
\hline $\mathrm{N}$ & 155036 & 151504 & 79560 & 76709 \\
\hline
\end{tabular}

Robust standard errors are in parenthesis. All the regressions include month dummies and household fixed effects. Columns (1) and (3) show the results of OLS estimation, while Columns (2) and (4) present 2SLS estimation results. The R squared reported for 2SLS estimations is the within R squared. F-stat is the statistic for the first-stage $\mathrm{F}$ test of excluded instruments. ${ }^{*}$ Statistically different from 0 at $10 \%$ significance; ${ }^{* *}$ Statistically different from 0 at $5 \%$ significance; ${ }^{* * *}$ Statistically different from 0 at $1 \%$ significance. 
Table 8: Impact of state restrictions - First stage results

\begin{tabular}{c|cc}
\hline \hline & \multicolumn{2}{|c}{ Dep. variable: price paid } \\
\hline & Non-menthol & Menthol \\
\hline Tax rate & $(1)$ & $(2)$ \\
& $0.6872^{* * *}$ & $0.7843^{* * *}$ \\
& $(0.0162)$ & $(0.0916)$ \\
\hline F-stat & & 73.35 \\
$\chi^{2}$-stat & 1791.88 & 9.63 \\
$\mathrm{R}^{2}$ & 5.02 & 0.0092 \\
$\mathrm{~N}$ & 0.1140 & 76709
\end{tabular}

Robust standard errors are in parenthesis. All the regressions include month dummies, the lagged quantity, and the state restrictions dummy. F-stat is the statistic for the first-stage $\mathrm{F}$ test of excluded instruments. *** Statistically different from 0 at $1 \%$ significance. 
Table 9: Price, reinforcement, and smoking restrictions - split samples

\begin{tabular}{|c|c|c|c|c|c|c|c|c|c|c|c|c|}
\hline & \multicolumn{2}{|c|}{ Age $\leq 52$} & \multicolumn{2}{|c|}{ Age $>52$} & \multicolumn{2}{|c|}{ Non-minority } & \multicolumn{2}{|c|}{ Minority } & \multicolumn{4}{|c|}{ Income $\leq \$ 21,250 \mid$ Income $>\$ 21,250$} \\
\hline & Non-me & $\mathrm{Me}$ & on-me & $\mathrm{Me}$ & Non-me & $\mathrm{Me}$ & Non-me & $\mathrm{Me}$ & Non-me & $\mathrm{Me}$ & Non-me & $\mathrm{Me}$ \\
\hline Rest & $-1.00^{* * *}$ & 0.27 & -0.37 & -0.78 & $-0.43^{* *}$ & -0.42 & $-1.46^{*}$ & -1.24 & -0.31 & -0.12 & -1.3 & 0.05 \\
\hline Price & $-1.93^{\circ}$ & 0.62 & $-1.61^{* *}$ & $-2.32^{* * *}$ & -1.78 & -1.96 & $-2.41^{* *}$ & 0.84 & -1.82 & -2.11 & -1.7 & -0.71 \\
\hline .Pa & $.25^{* * *}$ & $0.24^{*}$ & $0.34^{* * *}$ & $0.25^{* * *}$ & $0.30^{* * *}$ & $0.20^{* * *}$ & $0.26^{* * *}$ & $0.25^{* * *}$ & $0.34^{* * *}$ & $0.24^{* * *}$ & $0.18^{* * *}$ & $0.21^{* *}$ \\
\hline
\end{tabular}

Note: Income per household member; ${ }^{* * *}$ Statistically different from 0 at $1 \%$ significance,

**Statistically different from 0 at $5 \%$ significance 
Table 10: Estimation of the cessation hazard model

\begin{tabular}{l|cc}
\hline \hline & Dep. variable: survival dummy (cessation) \\
\hline \multirow{2}{*}{ Smoking restriction } & $(1)$ & $(2)$ \\
& Non-menthol & Menthol \\
\hline \multirow{2}{*}{ Price } & -0.0045 & 0.0354 \\
Births & $(0.0282)$ & $(0.0391)$ \\
& $0.0069^{*}$ & 0.0021 \\
log of Income & $(0.0038)$ & $(0.0014)$ \\
& $0.4171^{* * *}$ & $0.5732^{* * *}$ \\
Age & $(0.0747)$ & $(0.1013)$ \\
& $0.1571^{* * *}$ & $0.1868^{* * *}$ \\
College & $(0.0190)$ & $(0.0261)$ \\
& $-0.0035^{* * *}$ & $-0.0032^{*}$ \\
Minority & $(0.0012)$ & $(0.0018)$ \\
& $0.1083^{* * *}$ & -0.0052 \\
$\mathrm{R}^{2}$ & $(0.0299)$ & $(0.0419)$ \\
$\mathrm{N}$ & $0.1629^{* * *}$ & $-0.1415^{* * *}$ \\
\hline
\end{tabular}

Standard errors are in parentheses. All the specifications include a sixth-degree time polynomial to control for duration dependence. * Statistically different from 0 at $10 \%$ significance; ${ }^{* *}$ Statistically different from 0 at $5 \%$ significance; ${ }^{* * *}$ Statistically different from 0 at $1 \%$ significance. 
Table 11: Smoking restrictions - Sample of households with only one adult

\begin{tabular}{c|cccc}
\hline \hline & \multicolumn{4}{|c}{ Dep. variable: packs purchased per month } \\
\hline & \multicolumn{2}{|c}{ Non-menthol } & \multicolumn{3}{c}{ Menthol } \\
\hline & $(1)$ & $(2)$ & $(3)$ & $(4)$ \\
& OLS & 2 SLS & OLS & 2 SLS \\
\hline Smoking & $-1.0075^{* * *}$ & $-1.0050^{* * *}$ & -0.1068 & -0.2759 \\
restriction & $(0.3046)$ & $(0.3073)$ & $(0.2757)$ & $(0.3510)$ \\
& & & & \\
Price & $-0.8275^{* * *}$ & -0.7672 & $-0.0752^{* * *}$ & $-2.2760^{* * *}$ \\
& $(0.1434)$ & $(0.6886)$ & $(0.0279)$ & $(0.7368)$ \\
& & & & \\
Packs & $0.3507^{* * *}$ & $0.3509^{* * *}$ & $0.2017^{* * *}$ & $0.2055^{* * *}$ \\
t-1 & $(0.0540)$ & $(0.0542)$ & $(0.0120)$ & $(0.0163)$ \\
& & & & \\
\hline F-stat & & 833.68 & & \\
R & & 0.1507 & 0.7017 & 0.8489 \\
N & 52689 & 51524 & 31306 & 30342 \\
\hline
\end{tabular}

Robust standard errors are in parenthesis. All the regressions include month dummies and household fixed effects. Columns (1) and (3) show the results of OLS estimation, while Columns (2) and (4) present 2SLS estimation results. The R squared reported for 2SLS estimations is the within R squared. F-stat is the statistic for the first-stage $\mathrm{F}$ test of excluded instruments. ${ }^{*}$ Statistically different from 0 at $10 \%$ significance; ${ }^{* *}$ Statistically different from 0 at $5 \%$ significance; ${ }^{* * *}$ Statistically different from 0 at $1 \%$ significance. 
Table 12: Impact of state smoking restrictions - alternative specification

\begin{tabular}{c|ccc|ccc}
\hline \hline & \multicolumn{5}{|c}{ Dep. variable: packs purchased per month } \\
\hline & \multicolumn{5}{|c}{ Non-menthol } & \multicolumn{3}{c}{ Menthol } \\
\hline & $(1)$ & $(2)$ & $(3)$ & $(4)$ & $(5)$ & $(6)$ \\
& OLS & 2 SLS & GMM & OLS & 2SLS & GMM \\
\hline Rest. & $-0.4343^{* *}$ & $-0.4010^{* *}$ & $-1.3433^{* *}$ & 0.0365 & -0.2273 & 0.5376 \\
& $(0.2090)$ & $(0.2043)$ & $(0.6642)$ & $(0.2150)$ & $(0.2471)$ & $(0.6023)$ \\
& & & & & & \\
Price & $-0.6382^{* * *}$ & $-1.1973^{* * *}$ & $-0.7837^{* * *}$ & $-0.0559^{* * *}$ & $-1.1594^{* * *}$ & $-0.1216^{* *}$ \\
& $(0.0626)$ & $(0.4400)$ & $(0.2061)$ & $(0.0077)$ & $(0.4452)$ & $(0.0567)$ \\
& & & & & & \\
Pack & $0.2509^{* * *}$ & $0.2499^{* * *}$ & $0.1681^{* * *}$ & $0.1909^{* * *}$ & $0.1861^{* * *}$ & $0.0441^{* *}$ \\
t-1 & $(0.0172)$ & $(0.0173)$ & $(0.0620)$ & $(0.0091)$ & $(0.0095)$ & $(0.0176)$ \\
Pack & $0.1764^{* * *}$ & $0.1757^{* * *}$ & $0.0988^{* * *}$ & $0.1479^{* * *}$ & $0.1419^{* * *}$ & $0.0324^{* * *}$ \\
t-2 & $(0.0138)$ & $(0.0137)$ & $(0.0321)$ & $(0.0081)$ & $(0.0085)$ & $(0.0106)$ \\
\hline F-st & \multicolumn{7}{|c|}{1600.25} & & & 61.05 & \\
$\mathrm{R}^{2}$ & 0.6839 & 0.1496 & & 0.6967 & 0.2259 & \\
N & 147040 & 147040 & 108667 & 75357 & 75357 & 53676 \\
\hline
\end{tabular}

Robust standard errors are in parenthesis. All the regressions include month dummies and household fixed effects. Columns (1) and (4) show the results of OLS estimation. Columns (2) and (5) present 2SLS estimation results. Columns (3) and (6) show the results of the Arellano-Bond GMM estimator. The R squared reported for 2SLS estimations is the within $\mathrm{R}$ squared. F-stat is the statistic for the first-stage $\mathrm{F}$ test of excluded instruments. *Statistically different from 0 at $10 \%$ significance; ${ }^{* *}$ Statistically different from 0 at $5 \%$ significance; ${ }^{* * *}$ Statistically different from 0 at $1 \%$ significance. 